\title{
利用石墨悕致动器集群控制柔性机器人复杂形变
}

\author{
曲良体 1,2
}

1. 清华大学机械系, 北京 100084 ;

2. 清华大学化学系, 北京 100084

E-mail: 1qu@mail.tsinghua.edu.cn

\section{Programmable deformation of patterned bimorph actuator swarm}

\author{
Liangti $\mathrm{Qu}^{1,2}$ \\ ${ }^{1}$ Department of Mechanical Engineering, Tsinghua University, Beijing 100084, China; \\ ${ }^{2}$ Department of Chemistry, Tsinghua University, Beijing 100084, China \\ E-mail: lqu@mail.tsinghua.edu.cn \\ doi: 10.1360/TB-2020-0806
}

致动器是一种可以将各种环境刺激(例如湿度、光、 电场、磁场、 $\mathrm{pH} 、$ 溶剂等)转换成机械形变的自动化器件, 在 软体机器人, 微机电系统(MEMS) 和微流控芯片实验室等 领域显示出巨大的应用潜力 ${ }^{[1]}$. 传统的刺激响应致动器通 常是基于双层/多层结构, 靠不同材料在受到外界刺激时 的性质变化差异来实现驱动. 为了追求快速和大尺度的响 应形变, 研究者们不断地开发出许多新型的刺激响应材 料, 包括水凝胶、光热/电热型聚合物、相变材料等. 近年 来, 鉴于石墨烯高机械强度、透明性、导电/热性、生物兼 容性等优良的物理、化学性质, 基于石墨烯材料的碳基致 动器一直备受关注. 石墨烯材料的出现大大促进了致动器 领域的快速进步 ${ }^{[2]}$. 然而, 现有致动器的研究主要聚焦在 新型智能材料的研发, 对其精细变形的控制却很少研究. 已报道的石墨烯致动器也大多依赖于传统双层结构, 只能 实现弯曲、扭曲等简单形变 ${ }^{[3]}$, 限制了这类致动器的广泛
应用. 目前, 对致动器复杂形变的程序化控制仍然是领域 公认的难题.

吉林大学张永来教授课题组联合清华大学孙洪波教 授课题组 ${ }^{[4]}$ 针对上述难题展开了探索. 他们受细胞集群耦 合形变的启发, 通过图案化制备惰性层阵列, 研制了一种 湿度响应的石墨烯致动器集群, 利用个体致动器形变的耦 合作用, 实现了对整体智能薄膜复杂形变的程序化控制.

该石墨烯致动器是由具有特定几何形状和分布取向 的光聚合物(SU-8)微图案阵列与石墨烯氧化物 (GO)薄膜构 成. 其中单个的 SU-8图案彼此独立, 通过与 GO层形成双 层致动器结构, 在外界刺激下可发生主动变形, 致动器集 群 (致动器 1 , 致动器 $2 \cdots . .$. . 致动器 $n$ ) 的形变相对独立又相互 制约. 这样, 其整个结构的形变就可以通过SU-8图案的几 何形状、分布和取向灵活控制(图1).

为了进一步证明该思路对于实现复杂形变的效果, 他们
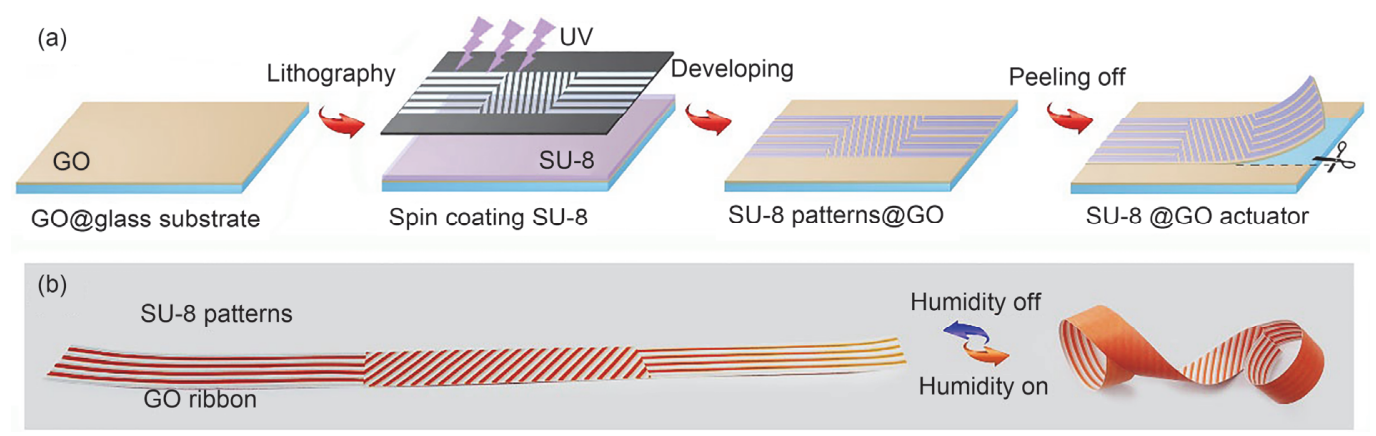

图 1 (网络版彩色)(a) 制备流程示意图. (b) 湿度刺激下, 纸质模型可控变形示意图 ${ }^{[4]}$

Figure 1 (Color online) (a) Schematic illustration of the fabrication of patterned SU-8/GO bilayer film using UV lithography. (b) The paper model of patterned SU-8/GO ribbon and its predictable moisture responsive deformation under humidity actuation ${ }^{[4]}$ 
将SU-8层图案化为具有不同几何结构、分布和方向的条纹, 实现了各种复杂且可预测的变形, 包括弯曲、扭转、卷取以 及两个或更多变形的组合(图2). 除此之外, 通过将几何图 形与非线性取向的SU-8条纹集成在一起, 还可以实现可控 的3D重构, 例如漏斗形状、非对称弯曲、胶囊形状等等.

作为实例展示, 该团队利用致动器群化原理制备了 可以随着“音乐”而翩翩起舞的舞蹈机器人和仿生毛毛虫机
器人, 充分展现出该方法对致动器形变的程序化控制. 除 了文中所示的例子之外, 利用他们提出的这种方案, 还有 很大的空间来设计和制造各种形式的机器人.

该工作提出的石墨烯致动器群化设计方案为致动器 复杂形变的程序化控制提供了新的思路, 大大扩展了现有 双晶片致动器在可穿戴智能设备、人造肌肉、柔性机器人 等众多领域的潜在应用能力.

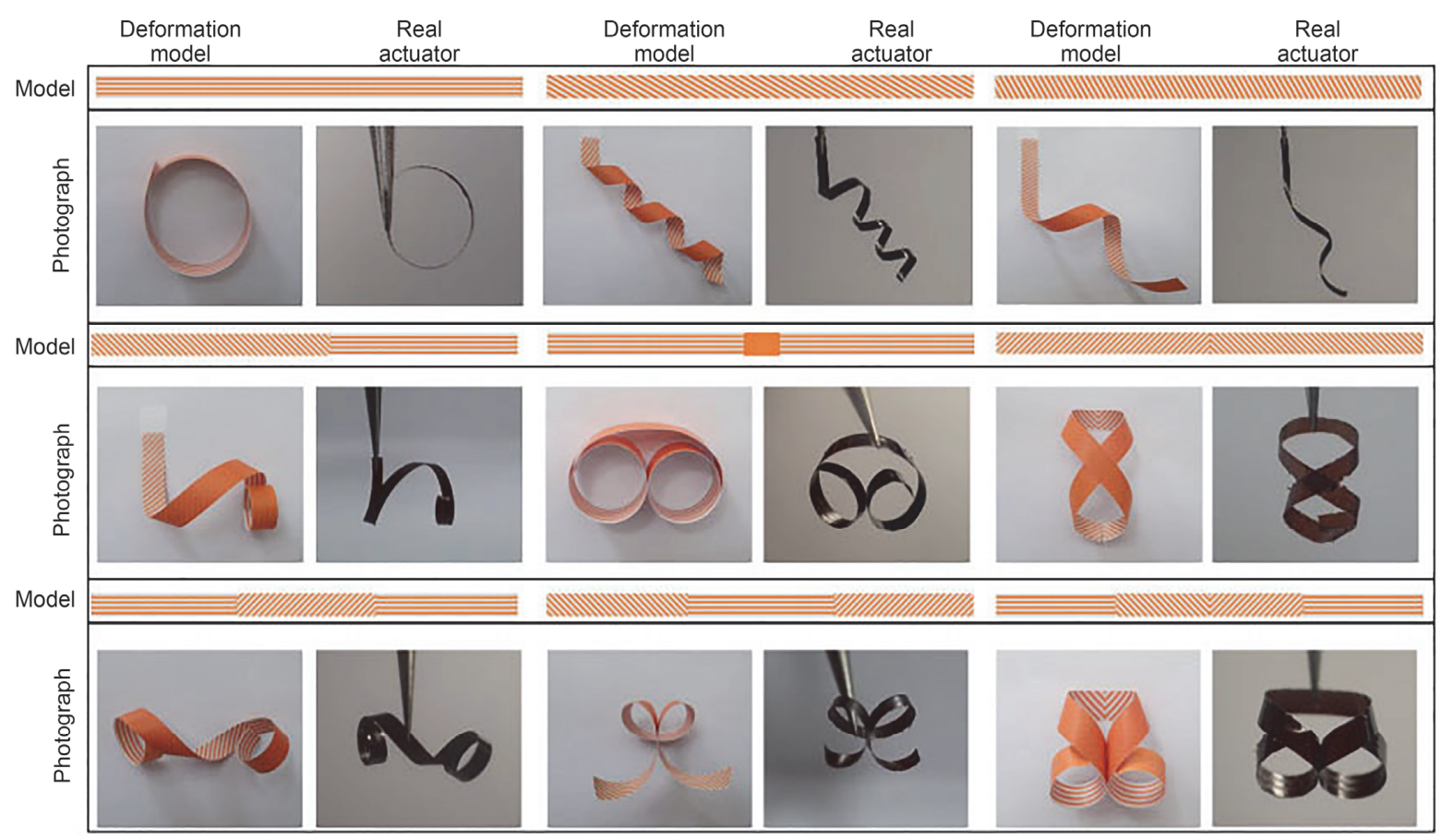

图 2 (网络版彩色)通过设计不同的SU-8 图案实现的复杂形变 ${ }^{[4]}$

Figure 2 (Color online) Complex deformations of different patterned SU-8/GO bilayers ${ }^{[4]}$

\section{参考文献}

1 Rus D, Tolley M T. Design, fabrication and control of soft robots. Nature, 2015, 521: 467-475

2 Zhang J, Song L, Zhang Z, et al. Environmentally responsive graphene systems. Small, 2014, 10: 2151-2164

3 Liang S, Qiu X, Yuan J, et al. Multiresponsive kinematics and robotics of surface-patterned polymer film. ACS Appl Mater Interfaces, 2018, 10: 19123-19132

4 Ma J N, Zhang Y L, Han D D, et al. Programmable deformation of patterned bimorph actuator swarm. Natl Sci Rev, 2020, 7: 775-785 